\title{
Normas técnicas para o processo de esterilização de materiais em unidades de saúde: uma proposta da enfermagem
}

\section{Normas técnicas para el proceso de esterilización de material en unidades de salud: una propuesta de enfermería}

\section{Technical standards for the process of material sterilization in health units: a proposal of nursing}

Márcia Danieli Schmitt ${ }^{1}$, Pâmela Nadia Binda ${ }^{2}$, Karen Cristina Jung Rech ${ }^{3}$ y Rosana Amora Ascari ${ }^{4}$

${ }^{1}$ Enfermeira. Pós-Graduada em Centro Cirúrgico, Central de Materiais de Esterilização e Sala de Recuperação Pós-Anestésica pelo Centro Sul Brasileiro de Pesquisa, Extensão e Pós-Graduação (CENSUPEG). Residente em Gerência de Serviços de Enfermagem

pela Universidade Estadual de Londrina (UEL). Chapecó, Santa Catarina - Brasil.E-mail: marciaschmitt@hotmail.com

${ }^{2}$ Enfermeira. Membro do Programa de Extensão Educação Continuada em Saúde UDESC. Chapecó, Santa Catarina - Brasil. E-mail:pame_sissi@hotmail.com

${ }^{3}$ Enfermeira. Pós-Graduada em Enfermagem do Trabalho pelo Centro Sul Brasileiro de Pesquisa, Extensão e Pós-Graduação (CENSUPEG). Membro do Programa de Extensão Educação Continuada em Saúde UDESC. Chapecó, Santa Catarina - Brasil. E-mail:karen_lua3@hotmail.com

${ }^{4}$ Enfermeira. Doutoranda em Enfermagem do Programa de Pós-Graduação em Enfermagem da Universidade Federal do Rio Grande do Sul (PPGEnf/UFRGS). Professora colaboradora do CENSUPEG e Professora Assistente do Departamento de Enfermagem da Universidade do Estado de Santa Catarina (UDESC). Membro do Grupo de Estudos sobre Saúde e Trabalho (GESTRA/ UDESC). Coordenadora do Programa de Extensão Educação Continuada em Saúde UDESC.. Chapecó, Santa Catarina - Brasil. E-mail: rosana.ascari@hotmail.com

Cómo citar este artículo en edición digital: Schmitt, M.D., Binda, P.N., Jung Rech, K.C. y Ascari, R.A. (2015). Normas técnicas para o processo de esterilização de materiais em unidades de saúde: uma proposta da enfermagem.

Cultura de los Cuidados (Edición digital), 19(43). Disponible en: <http://dx.doi.org/10.14198/cuid.2015.43.14>

Correspondencia: Rosana Amora Ascari. Universidade do Estado de Santa Catarina.

E-mail: rosana.ascari@hotmail.comou rosana.ascari@udesc.br

Recibido: 23/05/2015; Aceptado: 12/09/2015

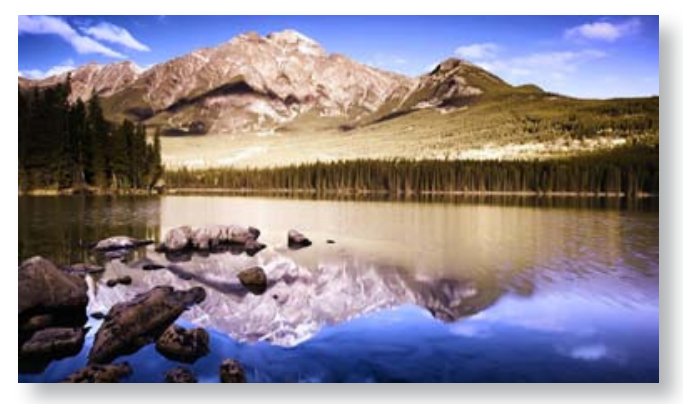

ABSTRACT

Objective: To organize a Technical Standard for the standardization of the sterilization process in Basic Health Units (BHU).

Method: An exploratory and descriptive study for the construction of guidance on the sterilization process, developed in partnership with the Continuing Education Program in Health, University of the State of Santa Catarina - UDESC, which followed the ethical recommendations of Resolution 466 / 2012 of the National Research Ethics Commission.

Results: It approaches issues related to the unidirectional material flow, standardization of the forms of cleaning and packaging, labeling, sterilization types, validation tests and record the sterilization process.

Conclusions: The technical standard will form the basis for training new employees, minimizing public costs wrapped in reprocessing dental, medical and hospital supplies and ensuring better health quality to users of the Unified Health System (UHS). 
Keywords: Technical Standards. Safety Management. Healt Management. Sterilization. Nursing.

\section{RESUMEN}

Objetivo: Organizar uma guia de Normas Técnicas para la estandarización del proceso de esterilización en Unidades Básicas de Salud (UBS).

Método: Se realizo um estudio exploratorio y descriptivo para la construcción de la guia de orientación sobre el proceso de esterilización, desarrollado en colaboración con el Programa de Educación Continua en Salud, Universidad del Estado de Santa Catarina (PECES / UDESC), que siguió las recomendaciones éticas de la Resolución 466 / 2012 de la Comisión Nacional de Ética de la Investigación.

Resultados: Se evidencian cuestiones relacionadas con el flujo de material unidireccional, la estandarización de las formas de limpieza y envasado, el etiquetado, los tipos de esterilización, las pruebas de validación y registrar el proceso de esterilización.

Conclusiones: La guia de orientación de normas técnicas constituirán la base para la formación de los nuevos empleados, lo que minimiza los costos públicos envueltos en el reprocesamiento, suministros médicos y hospitalarios dentales y garantizar una mejor calidad de la salud de los usuarios del Sistema Único de Salud (SUS).

Palabras clave: Normas Técnicas. Administración de la Seguridad. Gestión en salud. Esterilización. Enfermería.

\section{RESUMO}

Objetivo: Organizar uma Norma Técnica para a uniformização do processo de esterilização em Unidades Básicas de Saúde (UBS).

Método: Estudo exploratório e descritivo para a construção de diretriz sobre o processo de esterilização, desenvolvido em parceria com o Programa de Educação Continuada em Saúde da Universidade do Estado de Santa Catarina -UDESC, o qual seguiu as recomendações éticas da Resolução 466/2012 da Comissão Nacional de Ética em Pesquisa.

Resultados: Abordou-se questões relacionadas ao fluxo de materiais unidirecional, padronização das formas de limpeza e empacotamento, rotulagem, tipos de esterilização, testes de validação e registro do processo de esterilização.

Conclusões: A norma técnica servirá de base para treinamento de novos colaboradores, minimizando os custos públicos envoltos no reprocessamento de materiais odonto-médico-hospitalares e, assegurando melhor qualidade sanitária aos usuários do Sistema Único de Saúde (SUS).

Palavras chave: Normas Técnicas. Gerenciamento de Segurança. Gestão em Saúde. Esterilização. Enfermagem.

\section{INTRODUÇÃO}

Segundo a Associação Brasileira de Enfermeiros de Centro Cirúrgico, Recuperação Anestésica e Centro de Materiais de Esterilização (CME) a: "esterilização é o processo pelo qual os microrganismos são mortos a tal ponto que não seja mais possível detecta-lo no meio de cultura-padrão onde previamente haviam proliferado" (Sobecc, 2009). Portanto, o objeto não esta estéril na presença de qualquer microrganismo, não existindo assim, esterilização parcial (Padovese e Graziano, 2011).

A finalidade da esterilização é controlar a infecção, assim, considera-se que a assistência indireta prestada pela enfermagem que atua em CME tem igual importância da assistência 
direta prestada pela enfermagem ao paciente (khater e Uyeno, 2012).

As atividades realizadas para o reprocessamento de materiais odonto-médico-hospitalares expõe os profissionais a riscos ocupacionais (riscos químicos, físicos e biológicos) e a desorganização do processo de trabalho nesse setor influencia de maneira negativa a humanização dos trabalhadores e a qualidade do serviço prestado (Khater e Uyeno, 2012).

Visando a segurança do paciente e dos profissionais envolvidos no processamento de produtos para a saúde, a Resolução da Diretoria Colegiada - RDC no 15, de 15 de março de 2012, estabeleceu requisitos de boas práticas para o funcionamento desses serviços. Em seu Art.27 é estabelecido que "Todas as etapas do processamento de produtos para saúde devem ser realizadas por profissionais para os quais estas atividades estejam regulamentadas pelos seus conselhos de classe" (Brasil, 2012, p.6).

O Conselho Federal de Enfermagem COFEN, através da Resolução no 424/2012, normatiza as atribuições dos profissionais de enfermagem em CME e em empresas processadoras de produtos para saúde, cabendo aos Enfermeiros Coordenadores, Chefes ou Responsáveis por CME, entre outras coisas "Planejar, coordenar, executar, supervisionar e avaliar todas as etapas relacionadas ao processamento de produtos para saúde" (Cofen, 2012, s.p.).

A Politica Nacional de Atenção Básica determina atribuições especificas para cada categoria profissional, cabendo ao enfermeiro entre outras coisas, participar ativamente do gerenciamento de insumos necessários para o funcionamento das Unidades de Saúde da Família (Brasil, 2006).

Em pesquisas realizadas em 2011 acerca do processo de esterilização em 25 Unidades
Básicas de Saúde (UBS) num município do oeste catarinense, perceberam-se fragilidades a respeito do fluxo de materiais nas áreas destinadas à esterilização, diversidade de invólucros utilizados, falha na rotulagem do material e ausência da realização de testes para garantir esta esterilização (Ascari et al, 2012; Maldaner et al, 2013; Berlet et al, 2014). Além disso, os serviços de saúde pesquisados não dispunham de registro dos lotes e matérias reprocessados para o rastreamento destes em caso de necessidade (Berlet et al, 2014).

Considerando que as UBS do município em questão não dispõe de uniformização do processo de esterilização, nem de descrição de Normas Técnicas (NT) para nortear este processo, o que aumentam as chances de exposição profissional a riscos ocupacionais e põe em risco a qualidade dos serviços prestados aos beneficiários do Sistema Único de Saúde (SUS), o presente estudo apresenta uma proposta da enfermagem para organização de diretriz acerca da esterilização de materiais odonto-médico-hospitalares em Unidades Básicas de Saúde (UBS).

\section{MÉTODO}

Trata-se de um estudo exploratório e descritivo com abordagem qualitativa para o desenvolvimento de norma técnica sobre o processo de esterilização em UBS vinculadas à Secretaria de Saúde de um município no oeste catarinense.

Após várias leituras sobre o reprocessamento de materiais odonto-médico-hospitalares, com base em manuscritos científicos disponíveis on-line na Biblioteca Virtual em Saúde (BVS), no Scientific Eletronic Library online (SCIELO), Biblioteca Cochrane, Base de Dados de Enfermagem (BDENF), Literatura Latino-Americana e do Caribe em ciências 
da Saúde (LILACS), Medical Literature Analysis and Retrieval Sistem online (MEDLINE), Google Scholar, Latindex, Cumulative Index to Nursing and Allied Health Literature (CINAHL, Ebsco) e PubMed Central ${ }^{\circledR}$ (PMC) para a construção de diretriz sobre o processo de esterilização, os pesquisadores sentiram necessidade de compreender os objetivos da NT, genericamente conhecido por "protocolo" para a área de esterilização.

Neste sentido, os pesquisadores concluíram que a NT deve proporcionar aos trabalhadores um roteiro para atuação uniforme, bem como a definição de conceitos específicos desta área, permitindo maior controle na qualidade dos materiais reprocessados. Além disso, a NT possibilitará nortear o treinamento de novos colaboradores e servir de material para consulta em caso de dúvidas acerca das áreas que compõem a área física de esterilização, forma de limpeza, preparo e empacotamento, métodos de esterilização, guarda e distribuição dos artigos, bem como os testes e registros pertinentes ao reprocessamento de materiais Odonto-Médico-Hospitalares.

Este estudo foi desenvolvido no período de março a dezembro de 2013 em dois momentos. No primeiro momento os pesquisadores entraram em contato com a Secretaria de Saúde para expor a intenção de desenvolvimento de NT sobre o processo de esterilização em UBS vinculadas à secretaria municipal de saúde, o qual foi visto com bons olhos pela coordenação das Estratégias Saúde da Família (ESF) e pela coordenação da Atenção Básica da referida secretaria, ocasião em que se firmou um compromisso tácito de cooperação para revisão desta NT e viabilização de implantação em uma unidade piloto a ser selecionada a posterior.

No segundo momento os pesquisadores organizaram uma busca na literatura para ampliar o conhecimento sobre o processo de es- terilização, suas etapas e diretrizes a fim de garantir qualidade na descrição deste processo. Esta etapa contou com suporte do Programa de Educação Continuada em Saúde da Universidade do Estado de Santa Catarina (PECES/ UDESC), o qual contribuiu com a participação de docentes e discentes do curso de graduação em enfermagem, na ampliação da busca de material científico em base de dados on-line. Após a seleção de artigos pela equipe executora do PECES/UDESC no período de março a junho de 2013, os artigos selecionados foram encaminhados de forma digital para os pesquisadores, os quais avaliaram os manuscritos selecionados e os que apresentavam o desenvolvimento de boas práticas na esterilização de materiais foram considerados para o embasamento teórico desta NT.

A elaboração da NT deu-se nos períodos de julho a novembro de 2013, ocasião em que foi encaminhada à Secretaria Municipal de Saúde para avaliação pelo coordenador das UBS e da Atenção Básica. Em dezembro de 2014 a NT retornou com poucas sugestões para adequação à realidade local, as quais foram acatadas pelos pesquisadores.

$\mathrm{O}$ presente estudo seguiu as recomendações éticas da Resolução 466/2012 da Comissão Nacional de Ética em Pesquisa e por se tratar de pesquisa bibliográfica, todas as fontes utilizadas para a construção desta NT foram referenciadas ao término deste manuscrito.

\section{RESULTADOS E DICUSSÃO}

Para o desenvolvimento da NT para a área de esterilização em unidades básicas de saúde fez-se necessário conhecer a estrutura física das áreas destinadas à esterilização de materiais.

A planta física deve permitir um fluxo unidirecional dos artigos a serem reprocessados. Para tanto, recomenda-se que haja uma barreira entre a área suja e área limpa, e sempre 
que possível outra barreira entre a área limpa e área estéril (Guadagnin, Tipple e Souza, 2007).

A Agência Nacional de Vigilância Sanitária (ANVISA), através da RDC no 50 de 21 de fevereiro de 2002, descreve as atividades que devem ser desenvolvidas no CME. Os elementos que compõe a área física da CME, conhecido por área destinada ao processamento de materiais, são: recepção e expurgo, preparo e empacotamento, esterilização, guarda e distribuição de materiais (Brasil, 2002).

\section{Fluxograma dos artigos na CME e descrição das áreas de CME}

A CME é uma unidade no ambiente hospitalar responsável pelas seguintes ações: expurgo, limpeza e preparo, esterilização, guarda e distribuição dos materiais estéreis ou não estéreis das unidades de serviços que prestam atendimento ambulatorial ou não para o paciente. Este ambiente facilita o controle e padronização de técnicas da equipe de enfermagem no que diz respeito ao preparo e limpeza, assegurando a qualidade do material utilizado (Moura, 2011).

Figura 1 - Fluxo de Processamento de Artigos na $\mathrm{CME}$

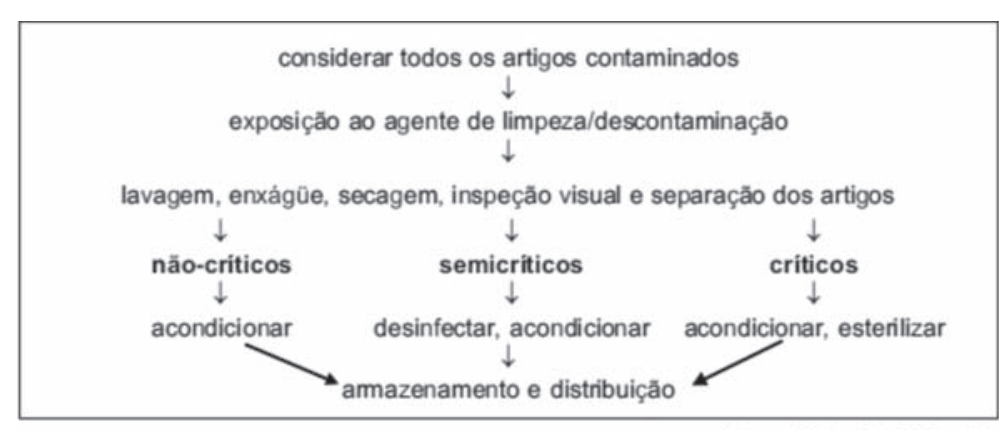

Fonte: (São Paulo, 2007, p.14)

de materiais contaminados provenientes das unidades consumidoras (Costa 2009).

Nessa área é desenvolvida a atividade de recepção, conferência e registro dos materiais; separação, desmontagem e imersão dos artigos em uma solução que contenha detergente enzimático; lavagem manual dos materiais individualmente; preparação dos materiais para a limpeza automatizada em máquina ultrassônica; preparação dos cestos com materiais na lavadora termodesinfectadora e seleção do ciclo de limpeza; inspeção dos materiais e relavagem quando ainda apresentarem sujidades; secagem dos materiais manualmente; preparação dos artigos para secagem automatizada e encaminhamento dos materiais para os serviços terceirizados (Costa, 2009).

A composição da área do expurgo segundo Kavanagh et al (2011), pode ser composta por um pia de granito que contenha três cubas de inox com duas torneiras e um misturador e duas cubas de inox, sendo uma com torneira três bicos de metal e outra com uma torneira e cinco bicos de metal para enxaguar borracha de aspiração, uma lavadora ultrassônica, um vaso sanitário com válvula hidra, uma janela com bancada de granito para o recebimento do material contaminado, três portas, três prateleiras, uma mesa de inox auxiliar, dois suportes para saco de hamper, uma bancada de madeira, três estrado de madeira.

A sala de recepção e limpeza dos materiais é

\section{Área de recepção e expurgo}

A área de recepção e expurgo é caracterizada como uma área destinada à recepção, conferência e limpeza ou lavagem e separação um dos locais mais contaminados da CME, pelas diversidades de materiais sujos com secreções16. Pode-se dimensionar o local de acordo com as suas funções, como por exemplo: 
- A área de recepção deve dispor de um ambiente de no mínimo $4 \mathrm{~m}^{2}$, com uma bancada de $1,0 \times 0,9 \mathrm{~m}$, alem de equipamentos de transporte com rodízios, recipiente perfuro cortantes e para resíduos biológicos, além da questão dos registros dos materiais recebido (Graziano, 2011).

- A Sala de Recepção, devolução, conferência do material deve ser dimensionada de acordo com a carga de trabalho, e o número de materiais diários, possuindo um acesso exclusivo para os materiais ainda não processados (Graziano, 2011).

- A área de limpeza deve ter área mínima de $15 \mathrm{~m}^{2}$, com torneira com água fria e quente, uma bancada com pia com as seguintes dimensões: $0,80 \mathrm{~m}$ de comprimento, $0,50 \mathrm{~m}$ de profundidade e 0,60 m de largura; equipamento de transporte com rodízio, ponto de água potável para enxágue com filtro de 0,2 micra, guichê de transferência dos produtos da área de limpeza para a área de preparo, recipiente perfurocortante, suporte para resíduo biológico, pistola de água com pressão para lavagem dos materiais com lúmen de ar comprimido ou oxigênio para secagem (Graziano, 2011).

As instituições devem padronizar horários do recebimento do material das unidades visando à organização da dinâmica do trabalho, favorecendo o funcionário no desenvolvimento das rotinas técnicas.

O escalado para esta função deve receber o material em horários preestabelecidos, conferindo e anotando as quantidades recebidas em cada secção. É imprescindível e obrigatória à utilização de Equipamento de Segurança Indi- vidual (EPI) durante todas as etapas do processo como as luvas de borrachas resistentes, luvas de procedimento, touca-turbante, propé impermeável, avental impermeável, óculos de proteção, protetor auricular, máscara e roupa privativa (Kavanagh et al, 2011).

\section{Área de preparo de materiais}

Segundo a RDC n50 de 2002 da Agência Nacional de Vigilância Sanitária, a área mínima para a área de preparo de matérias é de $12 \mathrm{~m}^{2}$, neste local os materiais já limpos são inspecionado, montados, acondicionados e identificados para a esterilização (Moura, 2011; Kavanagh et al, 2011).

As atividades de recepção dos materiais oriundos do expurgo; descarregamento dos equipamentos de limpeza e termodesinfecção; secagem dos materiais; inspeção visual dos artigos; verificação da integridade, funcionamento, lubrificação manual dos mesmos; separação e substituição dos artigos não conformes para avaliação e condutas; reposição e substituição das peças necessárias; montagem, conferência, embalagem dos materiais de assistência ventilatória; recepção e conferencia da roupa não estéril, montagem, embalagem e rotulagem dos pacotes são realizadas na área de preparo de materiais (Moura, 2011).

A sala de preparo é composta por prateleiras, mesas com gavetas, cadeiras giratórias, telefone, suporte de rolos de embalagem, suportes de fitas, seladoras, suporte de parede para folhas de embalagem (Kavanagh et al, 2011).

Neste ambienta recomenda-se o uso dos seguintes EPI: touca-turbante e luvas de procedimento. A sala deve ter o tamanho necessário para armazenar a quantidade e a diversidade dos materiais, a iluminação deve ser adequada para conferir a triagem, revisão e seleção dos materiais, combinando com a luz artificial 


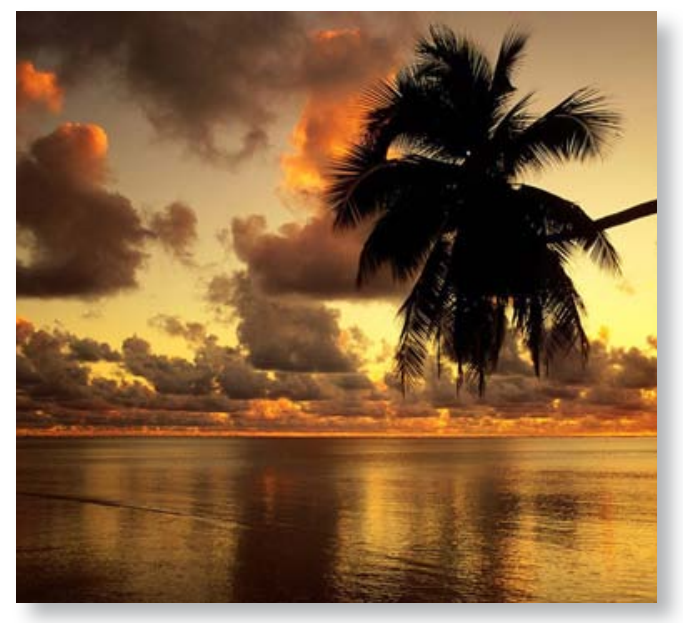

para evitar sombras e reflexos. Todo o material lavado e seco no expurgo deverá ser preparado utilizando embalagens descartáveis de acordo com o tamanho, forma e utilização do material padronizado pela comissão de controle de infecção. É necessário realizar o levantamento do uso diário de material pelas unidades de saúde, elaborando um controle interno do material, para evitar o acumulo de materiais esterilizados. As embalagens já fechadas dos materiais devem ser identificadas durante o preparo do pacote contendo o nome do funcionário, o tipo de artigo e a data de processamento (São pauolo, 2007; Kavanagh et al, 2011).

\section{Área de desinfecção de materiais (ácido pera- cético)}

$\mathrm{Na}$ área destinada a desinfecção de produtos para saúde, está relacionado com a utilização de produtos químicos cujos princípios ativos devem ser preconizados pelas legislações vigentes do Ministério da Saúde (MS). O ácido peracético é uma mistura de água, ácido acético, oxigênio e peróxido de hidrogênio se caracterizando como um desinfetante de alto nível, e uma das suas vantagens é a inexistência de resíduos, e ação rápida, ele age desnaturando e oxidando as proteínas, enzimas e outros metabólicos existentes nos materiais realizando as rupturas da permeabilidade da membrana celular (Minas Geraiss, 2010).

A sala de desinfecção química deve dispor uma área mínima de $4 \mathrm{~m}^{2}$, contendo uma bancada com cuba de lavagem dimensões: $0,80 \mathrm{x}$ $0,60 \mathrm{~m}$ e $0,50 \mathrm{~m}$ de profundidade), com ponto adicional de água com filtro e rodízio de transporte (GRAZIANO, 2011).

\section{Área de esterilização}

Esta área se destina à esterilização dos materiais após o preparo. A sala de esterilização de produtos para saúde deve ser dimensionada de acordo com o quantitativo e dimensão dos equipamentos, acrescida de $2,5 \mathrm{~m}^{2}$ para a circulação, além de prever a distância mínima de 0,50 m entre os equipamentos (São Paulo, 2007, Graziano, 2011).

A temperatura da área de esterilização deve ser inferior a $24^{\circ} \mathrm{C}$, e os profissionais devem usar os EPI's, como luvas grossas de tecido e de cano longo para evitar queimaduras como as luvas de Kevlar $^{\circledR}$ e touca turbante (Kavanagh et al, 2010).

Esta área deve dispor de incubadoras de indicadores biológicos e sistema para guarda dos registros dos monitoramentos do processo de esterilização e deve ser realizado diariamente com indicadores químicos e físicos (São Paulo, 2007).

\section{Área de guarda e distribuição}

Esta área tem por finalidade centralizar todos os artigos processados e esterilizados até sua posterior distribuição ás unidades consumidores, deve ser uma área restrita ao acesso e de uso exclusivo (Graziano, 2011). Deve ser composta por prateleiras, armários e cestos aramados, escadas e transporte com rodízio, as prateleiras devem estar disposta entre de 20 
$\mathrm{cm}$ a $25 \mathrm{~cm}$ do chão, $0,45 \mathrm{~cm}$ do teto e $5 \mathrm{~cm}$ das paredes laterais (Graziano, 2011).

Os produtos esterilizados devem ser armazenados em local limpo e seco, sob proteção da luz solar direta e submetidos à manipulação mínima (Ascari et al, 2012; Berlet et al, 2014; São Paulo, 2007). Os pacotes devem ser manuseados apenas quando estiver completamente fria, a distribuição de produtos para saúde processados na CME deve ser feito em recipientes fechados e em condições que garantam a manutenção da identificação e a integridade da embalagem (Maldaner et al, 2013). Para o armazenamento, utilizar armários fechados e devidamente identificados quando requisitados. Nesta área deve-se ter o cuidado de não permitir, no momento da distribuição, o cruzamento de artigos estéreis com artigos não estéreis (São Paulo, 2007).

\section{Descrição das atividades e atribuições da equipe de enfermagem}

Para o enfermeiro que atua na CME o gerenciamento da unidade é sua principal atividade, no que envolve as questões de planejamento, elaboração de instrumentos administrativos e operacionais, a supervisão, tomada de decisão, são elementos prescindíveis para a qualidade da assistência (Bartolomei e Lacerda, 2006).

\section{Atribuições gerais do enfermeiro}

Segundo a resolução COFEN no 421, de 15 de fevereiro de 2012, esta entre as atribuições do enfermeiro participar da elaboração de Protocolo Operacional Padrão (POP) para as etapas do processamento de produtos para saúde, com base em referencial científico atualizado e normatização pertinente, disponibilizando aos funcionários para consulta, também deverá participar da elaboração de sistema de registro (manual ou informatizado) da execução, para o monitoramento e controle das etapas de limpeza e desinfecção ou esterilização. É de responsabilidade do enfermeiro da CME propor e utilizar indicadores de controle de qualidade do processamento de produtos para saúde, acompanhar e documentar, as visitas técnicas de qualificação da operação e do desempenho de equipamentos da CME, ou da empresa processadora de produtos para saúde (Cofen, 2012).

Deve garantir a utilização de EPI, de acordo com o ambiente de trabalho da CME, elaborar termo de referência, ou emitir parecer técnico relativo à aquisição de produtos para saúde, equipamentos e insumos a serem utilizados, e atualizar-se, continuamente, sobre as inovações tecnológicas relacionadas ao processamento de produtos para saúde (Cofen, 2012).

Podemos citar ainda como atribuições gerais do enfermeiro dentro da unidade de esterilização a coordenação dos processos de trabalho, como também a os registros de passagem do plantão do período. Além disso, cabem a ele, questões de orientação sobre a rotina de trabalho na $\mathrm{CME}$, supervisionando as atividades em cada área, como o funcionamento dos equipamentos e materiais utilizados os avaliando e acompanhando a manutenção dos mesmos, checar os registros de esterilização e acompanhando e realizar os testes com os produtos, insumos e equipamentos (Costa e Fugulin, 2011).

Destaca-se a importância da verificação da incubação dos indicadores biológicos e anotação em livro próprio dos resultados. A supervisão do recebimento e o uso e devolução dos materiais consignados também é de responsabilidade deste profissional (Costa e Fugulin, 2011).

Questões de gestão e gerenciamento da unidade são atividades indispensáveis pelo 
enfermeiro, como a elaboração da escala diária de trabalho da equipe, realização e programação de capacitações e treinamentos, além da participação das compras de materiais e insumos para a unidade, avaliação e previsão do estoque de materiais consumidos pelo hospital, e a conferencia da programação diária de cirurgias a serem realizados disponibilizando roupas e materiais estéreis suficientes (Oliveira e Chaves, 2009).

A avaliação do desempenho dos profissionais também representa uma função de destaque, onde o enfermeiro também participa de questões gerenciais e administrativas do setor, como a participação de programas de prevenção de riscos ocupacionais e o desenvolvimento de pesquisas na central de materiais (Oliveira e Chaves, 2009).

\section{Atribuições gerais do técnico de enfermagem}

As atribuições do técnico de enfermagem dentro do setor estão relacionadas a receber o material oriundo dos outros setores, conferir, lavar, secar e embalar estes instrumentos, identificando de forma correta (Silva, Pimentel e Hermini, 2006).

Cabe também a esse profissional, anotar na folha de produção de materiais, identificar os hampers, preparar as cargas para a esterilização, esterilizar os materiais e retirar da autoclave e armazená-los de forma adequada. Além de distribuir os materiais estéreis nos setores, realizar a incubação e a leitura dos indicadores biológicos, a limpeza dos cestos, paredes, prateleiras do arsenal semanalmente, além de realizar a limpeza terminal de acordo com a rotina da unidade, a retirada de materiais com o prazo de validade da esterilização vencidos e a realização do teste de Bowie-Dick diariamente (Silva, Pimentel e Hermini, 2006).

\section{Invólucros recomendados de acordo com o tipo de esterilização}

De acordo com a Resolução RDC no 15 de 15 de março de 2012 da ANVISA, o invólucro deve permite a entrada e saída do ar e do agente esterilizante e impede a entrada de microrganismos, devendo estar regularizadas junto à ANVISA, para uso especifico em esterilização (Brasil, 2012).

Uma embalagem considerada ideal deve atender alguns requisitos para garantir as funções primárias de permitir e manter a esterilização do material: como permitir a penetração e remoção do agente esterilizante, promover barreira adequada aos microrganismos e seus veículos, deve resistir a rasgos, abrasões e perfuração, além de permitir o método de selagem eficiente que possibilite perceber a violação do pacote, proporcionando abertura de forma asséptica e não delaminar, a embalagem deve ser atóxica, inodora e não liberar corantes na sua utilização (Graziano, 2011).

A embalagem deve ser isenta de rasgos, furos, fissuras, dobras ou ter a sua espessura reduzida, possuir um nível aceitável de limpeza, não liberando partículas, ter relação com o custo-benefício do material, garantindo a proteção ao profissional durante o manuseio, repelir umidade, e se possível deve conter indicadores químicos. Disponibilizada em vários tamanhos,, a embalagem deve ser apropriada para o método de esterilização escolhido (Graziano 2011).

O responsável pela CME deve participar do processo de escolha da embalagem, para controlar a qualidade do material esterilizado, observando o custo-benefício do processo. A recomendação da escolha do invólucro se embasa no método de esterilização praticado. A figura 2 evidencia a compatibilidade entre o tipo de invólucro e o método de esterilização. 
Figura 2 - Compatibilidade entre embalagens e métodos de esterilização

\begin{tabular}{|c|c|c|c|c|c|c|}
\hline Embalagem & $\begin{array}{l}\text { Vapor } \\
\text { sob } \\
\text { pressão }\end{array}$ & $\begin{array}{l}\text { Calor } \\
\text { seco }\end{array}$ & $\begin{array}{l}\text { Óxido } \\
\text { de } \\
\text { etileno }\end{array}$ & $\begin{array}{l}\text { Plasma de } \\
\text { peróxido } \\
\text { de } \\
\text { hidrogênio }\end{array}$ & $\begin{array}{l}\text { Vapor a baixa } \\
\text { temperatura } \\
\text { de } \\
\text { formaldeído }\end{array}$ & $\begin{array}{l}\text { Radiação } \\
\text { ionizante }\end{array}$ \\
\hline Tecido algodão & Sim & Não & Năo & Não & Não & Não \\
\hline Contêiner rígido & Sim & Não & Sim & Sim & Sim & Sim \\
\hline Vidro refratário & Sim & Sim & Não & Não & Não & \\
\hline $\begin{array}{ll}\text { Papel grau } \\
\text { cirúrgico }\end{array}$ & Sim & Não & Sim & Não & Sim & Sim \\
\hline Papel crepado & Sim & Não & Sim & Não & Não & Sim \\
\hline Filmes & Sim & Não & Sim & Não & Sim & Sim \\
\hline Tyvek® & Sim & Não & Sim & Sim & Sim & Sim \\
\hline $\begin{array}{l}\text { Não } \quad \text { Tecido } \\
\text { (SMS) }\end{array}$ & Sim & Não & Sim & Sim & Sim & Sim \\
\hline Caixas metálicas & Sim & Sim & Sim & Sim & Sim & Sim \\
\hline
\end{tabular}

FONTE: (Graziano, 2010, p 98).

A escolha do invólucro para empacotamento depende das características dos artigos e do processo de esterilização a ser escolhido. As embalagens são necessárias para proteção dos artigos críticos após sua esterilização e devem atender as especificações do equipamento para garantir que o artigo foi esterilizado com segurança, considerando a permeabilidade para penetração e eliminação do agente esterilizante.

O papel grau cirúrgico ou laminado de polietileno ou polipropileno deve atender as recomendações e ser o material de escolha da unidade de esterilização. O tipo de embalagem de algodão cru ou musselina pode ser utilizado em campos duplos (duas camadas de tecido), conforme legislação Associação Brasileira de Normas Técnicas (ABNT). A cada utilização dos tecidos, os mesmos devem ser lavados, para a retirada de poeira e recomposição das fibras. As caixas metálicas para calor úmido devem ser perfuradas na sua parte superior ou inferior ou em ambas, e ser de uso exclusivo para esterilização em autoclave (Brasi, 1994).

A seleção das embalagens utilizadas no processo de esterilização de materiais deve levar em conta critérios de utilização como o tipo de esterilização e o material em que será envolvido, sempre observando as recomendações da $\mathrm{ABNT}$, na literatura foram encontrados os seguintes tipos de embalagem e sua validade varia de sete dias a 2 anos.

- Tecido de algodão: composto por tecido $100 \%$ algodão ou gramatura; é de baixo custo e memória, mas não é resistente à umidade e vulnerável a contaminação. Sua durabilidade é de até 65 reprocessamentos (Souza et al, 2010).

- Contêiner rígido: com filtro microbiano ou filtro Tyveck ${ }^{\oplus}$ são caixas de metal inoxidável, o alumínio dispõe de sistemas de filtros para saída de ar e entrada do vapor, dispensando o uso do invólucro externo e são termorresistentes; economizando tempo no preparo (dispensa a etapa da embalagem); segurança no transporte e manuseio; alta resistência; mecanismo de lacre; compatibilidade com os métodos de esterilização; reuso; e possibilidade de prazo de armazenamento longo (Souza et al, 2010).

- Vidro refratário: é reutilizável, possui alta proteção mecânica, mas seu uso é restrito (Souza et al, 2010).

- Papel grau cirúrgico: com face em filme plástico de Polietileno/ Poliéster ou filme de 
Polipropileno disponível em gramatura e em diversas formas e tamanhos, em bobinas ou envelopes; é de baixo custo e fácil visualização, com indicador químico monoparamétrico impregnado (Souza et al, 2010).

- Papel crepado: composto de $100 \%$ de celulose tratada é impermeável à água, álcool, PVPI, éter, $100 \%$ biodegradável, reciclável e maleável com alta filtragem microbiana. Apresenta baixa resistência mecânica, podendo furar ou rasgar com maior facilidade (Souza et al, 2010).

- Tyvek ${ }^{\circledR}$ : constituído em $100 \%$ polietileno em tripla camada, apresenta compatibilidade com diversos processos de esterilização, possui alta resistência mecânica, é de fácil visualização e pode ser impregnado com indicador biológico. Seu custo é elevado (Souza et al, 2010).

- Não Tecido (SMS): união de três camadas de não tecido $100 \%$ Polipropileno; tem excelente barreira antimicrobiana, alta permeabilidade aos agentes esterilizantes, maleabilidade, resistência mecânica à tração e à abrasão. Tem como desvantagens, a dificuldade de detecção da integridade da embalagem e não ser biodegradável (Souza et al, 2010).

- Caixas metálicas: é inoxidável, composta por alumínio, polímeros ou a combinação destes e são termo resistentes. Além disso, propicia melhor organização na sala de operação, em decorrência da diminuição do volume de invólucros, resistência mecânica; economia de espaço no armazenamento. Porém, tem custo elevado, apresenta risco de falha na vedação e exige inspeção visual constante (Souza et al, 2010).

\section{Testes recomendados para a validação do processo de esterilização}

Os testes recomendados são os testes químicos e biológicos, além da manutenção dos equipamentos e os registros do processo de esterilização (verificação mecânica). Os testes químicos indicam se ocorreu uma falha em potencial no processo de esterilização por meio da mudança de sua coloração, como o teste Bowie e Dick que devem ser utilizados diariamente no primeiro ciclo de esterilização em autoclaves (Canann et al, 2010).

Os testes biológicos consideram todos os parâmetros de esterilização, utilizam-se monitores e parâmetros críticos, tais como temperatura, pressão e tempo de exposição e, cuja leitura é realizada em incubadora, obtendo resultado em três horas, trazendo maior segurança na utilização dos materiais (Canann et al, 2010).

Os indicadores mecânicos ou físicos fazem parte o tempo (relógio e timer) das autoclaves, a temperatura, a pressão alcançada, e os relatórios impressos pelas máquinas, mas não representam uma resposta adequada para o controle da esterilização (Brasil, 2001).

Já os indicadores químicos, são substratos contidos em tiras de papel, que reagem a uma determinada temperatura, mudando de cor e são divididos em seis classes: Classe 1 - indicadores de processo como as fitas adesivas, utilizados em cada pacote. Demonstram apenas a passagem dos pacotes pelo processo. Como as fitas adesivas utilizadas externamente que mudam de cor (fitas zebradas). Classe 2 - indicadores para uso em testes específicos é utilizados em situações relevantes para o equipamento de esterilização, como é caso do teste de Bowie \& Dick (Minas Gerais, 2010).

$\mathrm{O}$ indicador de Classe 3 - indica de apenas um parâmetro, monitora um dos parâmetros críticos do processo de esterilização; Classe 4 - indicador de multiparâmetros ou multivariável, monitora dois ou mais parâmetros da esterilização. Classe 5 - indicadores integradores rastreiam todos os parâmetros críticos do processo de esterilização dentro de um intervalo 
especifico. E a Classe 6 - indicadores de simulação de ciclo, reagem a todos os parâmetros críticos (Minas Gerais, 2010).

Os indicadores biológicos são os únicos que asseguram a qualidade efetiva da esterilização, e todo seu processo deve ser documentando e deve ser realizado em todas as vezes que a máquina passar por alguma manutenção. Uma vez que os microrganismos são diretamente testados quanto ao seu crescimento ou não após a aplicação do processo (Barilli et al, 2009).

Estes indicadores podem ser divididos em categorias como os de $1^{\circ}$ geração - envelopes que contem tiras de papeis impregnadas de esporos (leitura em laboratório com 2 a 7 dias de incubação); Os de $2^{\circ}$ geração - incubados à $56^{\circ} \mathrm{C}$, por 48 horas, são ampolas que contem esporos secos e calibrados chamados de autocontidos. E os de $3^{\circ}$ geração - deve ser incubado por um período de 1 a 3 horas a $56^{\circ} \mathrm{C}$ e em seguida ser exposto à luz ultravioleta, a ausência de fluorescência indica que as condições de esterilização foram atingidas - a diferença para o de $2^{\circ}$ geração está na metodologia para detectar o crescimento bacteriano (Canann et al, 2010).

\section{Recomendação de registros acerca do pro- cesso de esterilização}

Cabe ao profissional da enfermagem realizar as atividades relacionadas à recepção, conferência e registro de materiais contaminados encaminhados pelas unidades assistenciais, realizando o registro do recebimento de materiais contaminados provenientes das unidades e a conferência dos mesmos pelo enfermeiro responsável (Costa, 2009).

Nos registros precisam conter o nome do material, tipo de esterilização, lote da esterilização, a validade do produto e o responsável pelo empacotamento do material. A cada ci- clo de esterilização faz-se necessário o registro com o lote, o seu conteúdo, o tempo de esterilização e a temperatura atingida pelo equipamento. As autoclaves mais recentes emitem esses registros de forma digital e impressa, os quais devem ser armazenados em local apropriado, além desses quesitos também os registrados o nome do operador do equipamento, os resultados dos testes biológicos realizados e dos indicadores químicos, e qualquer intercorrência que aconteceu no decorrer do processo de esterilização (Romano e Quelhas, 2009).

A qualidade do processo de esterilização depende do monitoramento do processo, a observação e o registro das atividades realizadas garantem a eficiência do processo, podendo-se avaliar todas as fases da esterilização com a finalidade de detectar possíveis falhas e aonde e como acontece. Recomenda-se o monitoramento biológico semanalmente das centrais de esterilização sendo obrigatório o uso de um livro de registros para a anotação dos resultados.

\section{Normas e rotinas de encaminhamento de materiais termossensíveis para esterilização em óxido de etileno (ETO)}

O Óxido de Etileno (ETO) é um gás utilizado como agente esterilizante de materiais médico-hospitalares, especialmente para materiais e artigos termossensíveis, sendo um produto altamente tóxico, facilmente inflamável e explosivo, além de ser carcinogênico, mutagênico, teratogênico e neurotóxico. Portanto, toda empresa que realiza esterilização por ETO, deve solicitar licença de funcionamento especifica para esse tipo de esterilização, através da Vigilância Sanitária Estadual, Municipal ou do Distrito Federal (Brasil, 1999).

Os materiais encaminhados para esterilização por ETO devem ser entregues limpos, seco, sem resíduo de material aderente, e 
quando tiver várias peças, estas precisam estar montadas.

Recomenda-se o armazenamento de caixas apropriadas, fechadas e identificadas, além do registro dos materiais a serem encaminhados para esterilização.

Devido à complexidade e o custo que envolve os equipamentos e instrumentais, é de grande importância todas as instituições de saúde utilizar um referencial teórico para conduzir o processo de esterilização de materiais, investindo na qualificação dos profissionais envolvidos nesse processo (Paurosi et al, 2014).

\section{CONSIDERAÇÕES FINAIS}

Os órgãos reguladores de produtos para saúde vêm aprimorando a qualidade técnica dos produtos para saúde, o que requer um reprocessamento de materiais odonto-médico-hospitalares com o menor risco possível tanto para os trabalhadores quanto para os usuários dos serviços de saúde.

Considerando a legislação vigente, $\mathrm{RDC} \mathrm{n}^{\circ}$ 15 de 15 de março de 2012, a qual prevê um fluxo de materiais unidirecional, padronização das formas de limpeza e empacotamento, do tipo de esterilização, aplicação de testes de validação do processo de esterilização que contemple os métodos físico, químico e biológico e registro adequado de todas as etapas deste processo, a presente norma técnica poderá ser utilizada pelos serviços de saúde de atenção básica para treinamento de novos colaboradores, auxiliando as unidades básicas de saúde na definição das áreas que compõem um centro de material e esterilização, das formas de limpeza, na escolha dos invólucros de acordo com o método de esterilização praticado, na identificação/rotulagem do produto para saúde, na aplicação de testes de validação, bem como no registro e rastreamento dos produtos processados, minimizando os custos públi- cos envoltos no reprocessamento de materiais odonto-médico-hospitalares, e principalmente, assegurando melhor qualidade sanitária aos usuários do SUS.

\section{REFERENCIAS}

- Ascari, R.A., Silva, O.M., Azevedo Junior, L., Berlet, L.J., Maldaner, C., Mai, S. (2012). Fluxo de materiais odontomédico-hospitalares durante seu reprocessamento em unidades básicas de saúde. Udesc em Ação, 6 (1), 1-16.

- Brasil. Agência Nacional de Vigilância Sanitária (ANVISA). (2002). Resolução - RDC $n^{\circ} 50$ de 21 de fevereiro de 2002, que aprova o regulamento técnico destinado ao planejamento, programação, elaboração, avaliação $e$ aprovação de projetos físicos de estabelecimentos assistenciais de saúde. Brasilia: ANVISA. Disponível em: http://portal.anvisa.gov.br/wps/wcm/connect/ ca36b200474597459fc8df3fbc4c6735/RDC+N\%C $2 \% \mathrm{BA} .+50,+\mathrm{DE}+21+\mathrm{DE}+\mathrm{FEVEREIRO}+\mathrm{DE}+2002$. pdf?MOD=AJPERES

- Brasil. Agência Nacional de Vigilância Sanitária (ANVISA). (2012). Resolução - RDC $n^{\circ} 15$, de 15 de março de 2012, que dispóe sobre requisitos de boas práticas para o processamento de produtos para saúde e dá outras providências. Brasilia: ANVISA. http://bvsms.saude.gov.br/ bvs/saudelegis/anvisa/2012/rdc0015_15_03_2012.html

- Brasil. Ministério da Saúde. Coordenação de Controle de Infecção Hospitalar. (1994). Processamento de artigos e superfícies em estabelecimentos de saúde. 2. ed. Brasília, Ministério da Saúde. Disponível em: http://www.anvisa. gov.br/servicosaude/controle/processamento_artigos. pdf

- Brasil. Ministério da Saúde. Secretária de Assistência à Saúde. Coordenação-Geral das Unidades Hospitalares Próprias do Rio de Janeiro. (2001). Orientações gerais para Central de Esterilização. Brasília: Ministério da Saúde. Disponível em: Disponível em: http://www. cro-rj.org.br/biosseguranca/Orientacoes $\% 20$ Gerais $\% 20$ para $\% 20$ Central $\% 20 \mathrm{de} \% 20$ Esterilizacao.pdf

- Brasil. Ministério da Saúde. Secretaria de Atenção à Saúde. Departamento de Atenção Básica. (2006). Política nacional de atenção básica. Brasília: Ministério da Saúde. 
Disponível em: http://bvsms.saude.gov.br/bvs/publicacoes/politica_nacional_atencao_basica_2006.pdf

- Brasil. Agência Nacional de Vigilância Sanitária (ANVISA). (1999). Portaria Interministerial 482 de 16/4/1999. Esterilização por óxido de etileno. Brasilia: ANVISA. Disponível em: http://www.sobed.org.br/web/arquivos_antigos/pdf/37.pdf

- Barilli, A.L.A., Nascimento, G.M., Pereira, M.C.A., Liporaci, M.M.P.M., Lazzarini, M.P.T. (2009). Prefeitura Municipal de Ribeirão Preto-SP. Secretaria Municipal da Saúde. Comissão de Controle de Infecção. Subcomissão de Qualificação de Esterilização em Autoclaves da CCI-SMS. Manual de Qualificação de Esterilização em Autoclaves. Ribeirão Preto: Secretaria Munbicipal de Saúde. Disponível em: http://www.ribeiraopreto.sp.gov.br/ssaude/ comissao/desin/m-pdf/m-autoclave-gibi.pdf

- Batolomei, S.R.T., Lacerda, R.A. (2006). Trabalho do enfermeiro no Centro de Material e seu lugar no processo de cuidar pela enfermagem. Rev Esc Enferm USP, 40 (3), 412-417.

- Bertel, L.J., Ascari, R.A., Silva, O.M., Trindade, L.L., Krauzer, I.M., Jacoby, A.M. (2014). Factors that influence the quality of the sterilization process. J Nurs UFPE on line, Recife, 8 (7), 1997-2003.

- Canaan, J.M.M., Pestana, K.C., Silva, M.I., Raddi, M.S.G. (2010). Avaliação do processo de esterilização por autoclavagem utilizando indicadores biológico e químico. Seminário Anual do PGSST-UNESP. Universidade Estadual Paulista Júlio de Mesquita Filho. Disponível em: file://C:/ Users/Rosana/Downloads/autoclave\%20(4).pdf

- Cofen - Conselho Federal de Enfermagem. (2012). Resolução COFEN No 424/2012. Brasília: CFE. Disponível em: http://novo.portalcofen.gov.br/resoluo-cofenn-4242012_8990.html

- Costa, J.A. (2009). Atividades de Enfermagem no Centro de Material e Esterilização: subsídios para o dimensionamento de pessoal. Escola de Enfermagem da Universidade de São Paulo. São Paulo. Disponível em: www.teses.usp. br/teses/disponiveis/7/7131/tde.../Janaina_Anchieta.pdf - Costa, J.A., Fugulin, D.M.T. (2011). Atividades de enfermagem em centro de material e esterilização: contribuição para o dimensionamento de pessoal. Acta Paul.
Enferm, 24 (2), 249-256.

- Guadagnin, S.V.T., Tipple, A.F.V., Souza, A.C.S. (2007). Avaliação arquitetônica dos centros de material e esterilização de hospitais do interior do estado de Goiás. Rev. Eletr. Enferm, 9 (3), 656-673.

- Graziano, K.U., Silva, A., Psaltikidis, E.M. (orgs.). (2011). Enfermagem em Centro de Material e Esterilização. Barueri, SP: Manoele. (Série Enfermagem).

- Kavanagh, C.M.G. (2011). Elaboração do manual de procedimentos em central de materiais e esterilização. 2 ed. São Paulo: Editora Atheneu.

- Khater, M., Uyeno, C.G.A. (2012). A humanização em foco na assistência indireta da equipe de enfermagem. III Congresso de Humanização e II Jornada Interdisciplinar de Humanização. Disponível em: http://anais.congressodehumanizacao.com.br/files/2012/08/PDF-33.pdf

- Maldaner, C., Berlet, L.J., Ascari, R.A., Klein, M.L., Savian, B.A., Silva, O.M. (2013). Invólucros para esterilização de materiais odonto-médico-hospitalares. Rev Saúde Pública Santa Catarina, 6 (3), 61-70.

- Minas Gerais. Secretária Municipal de Saúde de Contagem-MG. Grupo de Estudos em Centro de Material e Esterilização da Secretária Municipal de Saúde de Contagem. (2010). Comissão Municipal de Controle de Infecção em Serviços de Saúde - CMCISS. Manual de Processamento de Artigos em Serviços de Saúde. Minas Gerais: Contagem. Disponível em: http://novo.contagem. mg.gov.br/arquivos/downloads/manual_cme.pdf

- Moura, M.L.P.A. (2011). Enfermagem em centro de material e esterilização. 10 ed. São Paulo: Editora Senac São Paulo.

- Oliveira, N.C., Chaves, L.D.P. (2009). Gerenciamento de recursos materiais: o papel da enfermeira de unidade de terapia intensiva. Rev. Rene, Fortaleza, 10 (4), 19-27.

- Padoveze, M.C., Graziano, K.U. Aspectos conceituais e microbiológicos relacionados ao processamento de materiais utilizados na assistência à saúde. In: Graziano, K.U., Silva, A., Psaltikidis, E.M. (Org.). (2011). Enfermagem em Centro de Material e Esterilização. São Paulo: Manole.

- Paurosi, D.R., Ascari, R.A., Silva, O.M., Ascari, T.M. (2014). Diretrizes operacionais para uma central de Ma- 


\section{Cultura de las Cuidados}

terial e esterilização odontológica: Uma proposta da enfermagem. Revista UNINGÁ Review, 17 (2), 5-10.

- Romano, J.C., Quelhas, M.C.F. (2014). Monitoramento dos Métodos de Esterilização. Disponível em: http://www. hospvirt.org.br/enfermagem/port/testes.html

- São Paulo. Secretaria Municipal da Saúde. Comissão de Controle de Infecção. (2007). Protocolo de Processamento de Artigos e Superfícies nas Unidades de Saúde. São Paulo: Ribeirão Preto-SP. Disponível em: http://www. ribeiraopreto.sp.gov.br/ssaude/comissao/desin/esterilizacao.pdf

- Silva, M.C.F.G., Pimentel, E.C., Hermini, A. (2014). Centro de atenção integral à saúde da mulher. Gerenciamento da CME. Disponível em: ftp://ftp.caism.unicamp.br/
pub/CME/CME\%2034\%20-\%20Gerenciamento \%20 da\%20cme.pdf

- Sobecc - Sociedade Brasileira de Enfermeiros de Centro Cirúrgico, Recuperação Anestésica e Centro de Material e Esterilização. (2009). Práticas Recomendadas SOBECC / Sociedade Brasileira de Enfermeiros de Centro Cirúrgico, Recuperação Anestésica e Centro de Material e Esterilização. $5^{\mathrm{a}}$ edição. São Paulo: SOBECC.

- Souza, A.S., Sória, D.A.C., Araújo, J.O., Silva, M.T., Andrade, N.C. (2010). Embalagens para esterilização: suas aplicações e recomendações na prática hospitalar. Rev. Pesquisa: Cuidado é Fundamental, 2 (Ed. Supl.), 316-319. Disponível em: http://www.seer.unirio.br/index.php/cuidadofundamental/article/view/931/pdf_139

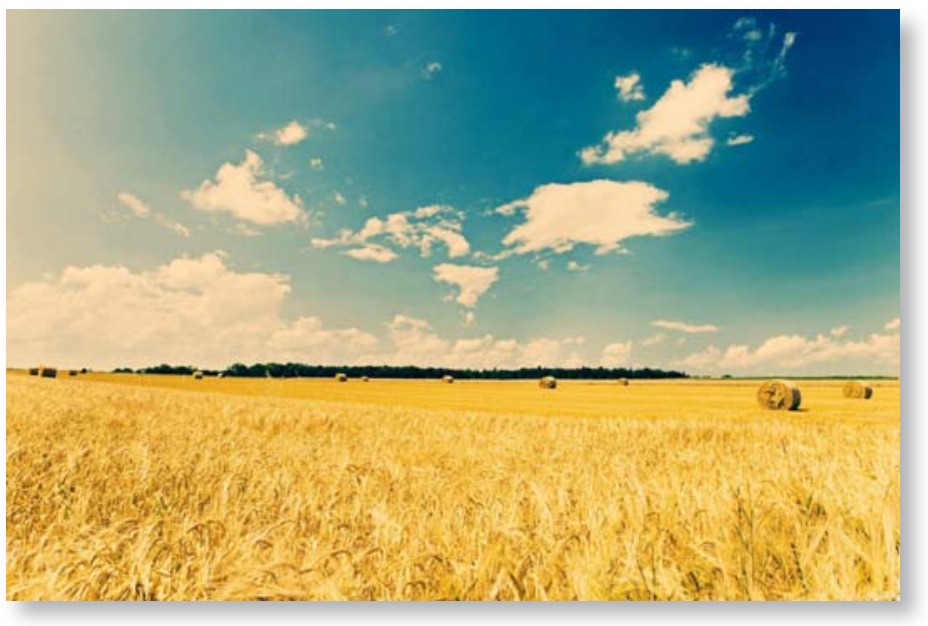

